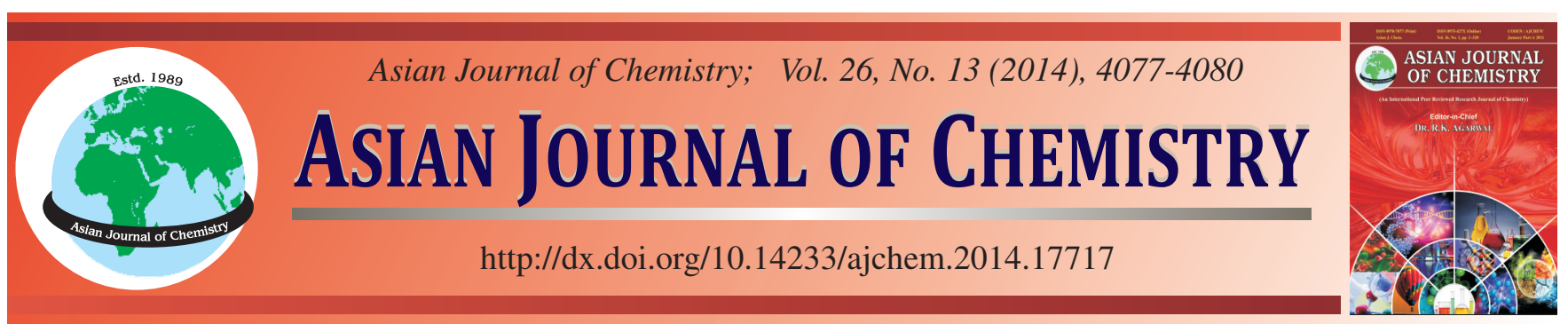

\title{
Determination of Uranium, Plutonium, Cesium and Europium Isotopes in Nuclear Fuel Claddings by Isotope Dilution Mass Spectrometry and $\boldsymbol{\gamma}$-Ray Spectrometry $\dagger$
}

\author{
Jung Suk Kim*, Young Shin Jeon, Yang-Soon Park, Jai Il Park and Yong Joon Park
}

Nuclear Chemistry Research Division, Korea Atomic Energy Research Institute, Daedeok-daero 989-111, Yuseong-gu, Daejeon 305-353, Republic of Korea

*Corresponding author: Fax: +82 42 8688148; E-mail: njskim1@ kaeri.re.kr

\begin{abstract}
Isotope dilution mass spectrometric (IDMS) and $\gamma$-ray spectrometric (GRS) methods have been used for the determination of uranium, plutonium, cesium and europium isotopes in cladding from pressurized water reactor nuclear fuel irradiated in a power reactor. A dissolution of cladding samples was performed through a two-step procedure, washing with $8 \mathrm{M} \mathrm{HNO}_{3}$ at $90{ }^{\circ} \mathrm{C}$ and dissolving with $2 \mathrm{M} \mathrm{HF}$ at $25^{\circ} \mathrm{C}$ followed by dissolving with aqua regia at $90{ }^{\circ} \mathrm{C}$. After the dissolution procedure, the chemical composition of insoluble residue $(<2 \mathrm{wt}$. \%) was identified using a $\gamma$-ray spectrometry. The isotopic compositions and their contents of uranium and plutonium and the activities of cesium and europium isotopes found in the dissolving and washing solutions of the cladding specimen from high burnup nuclear fuel, were compared with those found in a dissolving and washing solutions of the cladding specimen from low burnup nuclear fuel.
\end{abstract}

Keywords: Isotope dilution mass spectrometry, $\gamma$-Ray spectrometry, Fuel cladding, Uranium, Plutonium, Cesium, Europium.

\section{INTRODUCTION}

Pressurized water reactor (PWR) cladding is made of zirconium alloy (zircaloy) and there are three main types of activities associated with it i.e., activation products, fission products and actinides. The amounts of activation products depend on the irradiation conditions and the neutron flux. The amounts of fission products and actinides depend on the quantity of spent fuel remaining in the cladding after de-cladding. Some fission products will be driven into the cladding by fission recoil and there is also likely to be a penetration of the cladding as a result of diffusion along grain boundaries. $\alpha$-Spectra of the cladding surfaces were obtained for pressurized water reactor cladding samples and the results have shown very little penetration of the zircaloy surface by $\alpha$-emitters ${ }^{1}$. A quantitative evaluation of radionuclides in spent fuel cladding is of great importance with respect to the final waste disposal and environmental aspects and the recycling of the cladding. In the decontamination practice to reduce the hazards arising from the radioactivity in spent fuel claddings, the distribution of actinides in the fuel cladding is of particular importance ${ }^{1,2}$.

In this work, washing and dissolving experiments have been performed to evaluate the distribution of $\mathrm{U}, \mathrm{Pu}, \mathrm{Cs}$ and $\mathrm{Eu}$ isotopes on the surface and the interior of spent nuclear fuel cladding specimens. The isotopic compositions and their contents of $\mathrm{U}$ and $\mathrm{Pu}$ and the activities of $\mathrm{Cs}$ and Eu isotopes ( $\gamma$-emitters) in the washed solutions as well as the dissolved solutions were determined using isotope dilution mass spectrometric (IDMS) and $\gamma$-ray spectrometric (GRS) methods, respectively.

\section{EXPERIMENTAL}

Certified ${ }^{233} U$ (99.470 atom \%) spike was obtained from Oak Ridge National Laboratory (ORNL). This spike solution was prepared by dissolving their oxides in $8 \mathrm{M} \mathrm{HNO}_{3}-0.01 \mathrm{M}$ HF. NBL CRM $129 \mathrm{U}_{3} \mathrm{O}_{8}$ powder (New Brunswick Laboratory) and a $U$ standard solution (Spex Industries Inc.) were used as a standard reference material for the U. A certified ${ }^{242} \mathrm{Pu}$ spike solution (99.9033 atom \%, IRMM-044) was obtained from the Institute for Reference Materials and Measurements ${ }^{3}$. Two kinds of cladding specimens, H-1 (low burnup fuel cladding) and H-2 (high burnup fuel cladding) were prepared from the spent nuclear fuel rods of a PWR type. S-1, S-2 and S-3 cladding wastes, which were previously decontaminated by refluxing with nitric acid, were prepared for the dissolution experiments. The isotopic compositions of $\mathrm{U}$ and $\mathrm{Pu}$ in the unspiked and spiked samples were determined using a thermal 
ionization mass spectrometer of a Finnigan MAT 262 type. The activity of $\gamma$-emitters for the washed and dissolved solutions from the fuel claddings was measured with a high purity Ge coaxial detector (EG \& G ORTEC) connected to a multichannel analyzer.

The basic processes in the analytical laboratory for the determination of $\mathrm{U}, \mathrm{Pu}$ and $\gamma$-emitters are shown in Fig. 1 . The primary experiment was carried out with samples of S-1S-3, to establish the optimum conditions for complete dissolution of cladding specimen. A sample having been precisely weighed was placed into a $100 \mathrm{~mL}$ dissolution flask including a dissolving medium in Table-1. After refluxing, the insoluble residues remaining finally in the flask were collected. Washing and dissolution experiments with cladding specimens of $\mathrm{H}-1$ and $\mathrm{H}-2$ were carried out according to the processes in Fig. 1. An aliquot of the washed and dissolved solutions was transferred from the shielded facility into a glove box for the acid treatment and chromatographic separation. The anion exchange separation of $\mathrm{U}$ and $\mathrm{Pu}$ was carried out by the procedures shown in Fig. 2. After the mass spectrometric measurement of each portion isolated from the unspiked and spiked sample solutions, the concentrations of $\mathrm{U}$ and $\mathrm{Pu}$ in the sample solutions were determined using the isotope dilution method. On the other hand, for the determination of $\gamma$-emitters including $\mathrm{Cs}$ and Eu isotopes, the $\gamma$-ray activity for an aliquot of the washed and dissolved solutions was measured with a high purity Ge coaxial detector.

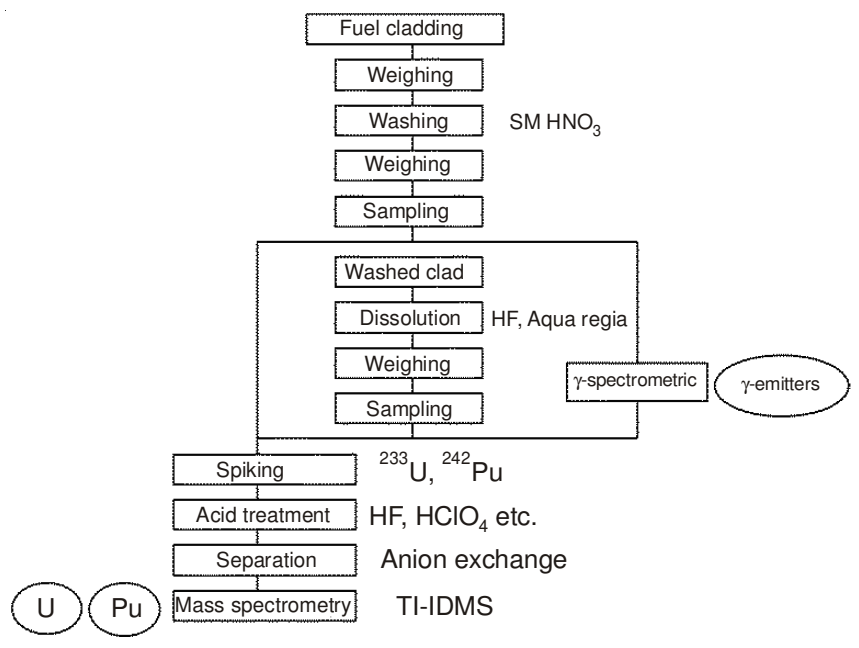

Fig. 1. Analytical processes for the determination of $U, P u$ and $\gamma$-emitters in a cladding sample

TABLE-1

DISSOLUTION MEDIA FOR CLADDING WASTE SAMPLES

Wt. (g) Medium

S-1 $0.165 \quad 3 \mathrm{M} \mathrm{HNO}_{3}-3 \mathrm{M} \mathrm{HF}, 90^{\circ} \mathrm{C}, 24 \mathrm{~h}$

$\mathrm{S}-2 \quad 0.162 \quad 3 \mathrm{M} \mathrm{HNO}_{3}-2 \mathrm{M} \mathrm{HF}-5 \mathrm{M} \mathrm{HCl} 90^{\circ} \mathrm{C}, 20 \mathrm{~h}$

S-3 $0.154 \quad 1$ st: $2 \mathrm{M} \mathrm{HF} 25^{\circ} \mathrm{C} 18 \mathrm{~h}, 90^{\circ} \mathrm{C} 4 \mathrm{~h}, 2$ nd: Aqua regia $8 \mathrm{~h}$

\section{RESULTS AND DISCUSSION}

$\boldsymbol{\gamma}$-Emitters in insoluble residue of cladding waste: The corrosion rate of zirconium alloy in nitric acid is very small because a very resistive layer of zirconium oxide prohibits the direct attack of the metal by the aggressive solution. However,

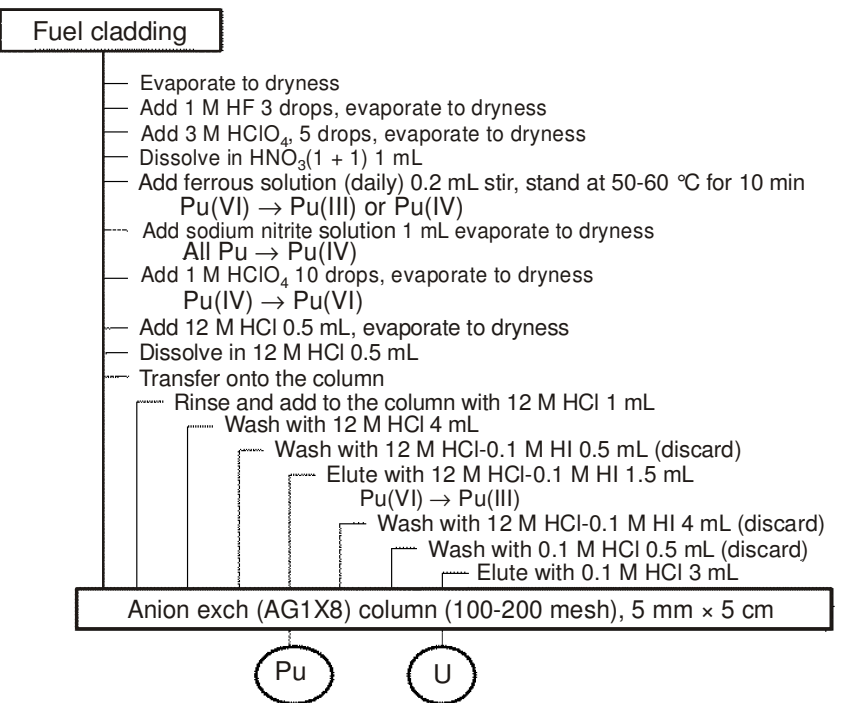

Fig. 2. Analytical scheme for the $\mathrm{U}$ and $\mathrm{Pu}$ separations in a cladding sample

the rate can be dramatically enhanced by adding HF to the solution $^{3-5}$. From the dissolution experiments in this work, the yield of the total residue by S-3 was found to be less than $2 \%$ of the weight of the fuel cladding originally taken for dissolution and the yields of the total residue by S-1 and S-2 were found to be above $3 \%$. Therefore, it can be concluded that two-step dissolution procedure using $\mathrm{HF}$ and aqua regia is very effective for the dissolution of cladding samples. As shown in Fig. 3, the insoluble residue mainly consists of ${ }^{60} \mathrm{Co},{ }^{106} \mathrm{Ru},{ }^{125} \mathrm{Sb}$, ${ }^{134} \mathrm{Cs},{ }^{137} \mathrm{Cs},{ }^{144} \mathrm{Ce},{ }^{154} \mathrm{Eu}$ and ${ }^{95} \mathrm{Zr}$ from the GRS, which is similar to that observed by Hirabayashi et al. ${ }^{1}$ and Jenkins \& Brown ${ }^{2}$.

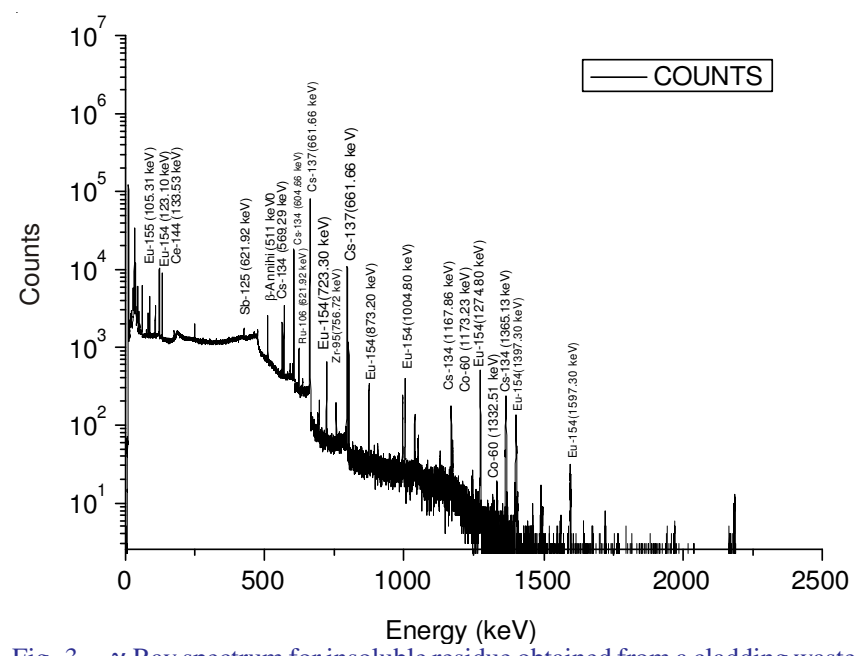

Fig. 3. $\quad \gamma$-Ray spectrum for insoluble residue obtained from a cladding waste sample

$\boldsymbol{\gamma}$-Emitters in washed and dissolved solutions of fuel cladding: The activities of $\gamma$-emitters found in the washed and dissolved solutions of $\mathrm{H}-1$ and $\mathrm{H}-2$ claddings are summarized in Table-2. The activities of $\gamma$-emitters in the washed and dissolved solutions from $\mathrm{H}-2$ cladding, that is, H-2(W) and $\mathrm{H}-2$ (D), including the fission products ${ }^{134} \mathrm{Cs},{ }^{137} \mathrm{Cs},{ }^{154} \mathrm{Eu},{ }^{155} \mathrm{Eu}$ and ${ }^{125} \mathrm{Sb}$ and activation products such as ${ }^{60} \mathrm{Co}$ and ${ }^{95} \mathrm{Zr}$, are higher than those obtained from $\mathrm{H}-1$, that is, $\mathrm{H}-1(\mathrm{~W})$ and H-1(D). Therefore, it can be concluded that the fission products and activation products in the claddings increase with increasing 


\begin{tabular}{ccccc}
\hline \multicolumn{5}{c}{ TABLE-2 } \\
DISTRIBUTION OF $\gamma$-EMITTERS IN CLADDING SAMPLES \\
\hline \multirow{2}{*}{ Nuclide } & $\mathrm{H}-1(\mathrm{~W})$ & $\mathrm{H}$ Activity $(\mathrm{Bq} / \mathrm{g}$-sample) & $\mathrm{H}$-1(D) & $\mathrm{H}-2(\mathrm{D})$ \\
\cline { 2 - 5 } & $6.46 \times 10^{4} \pm 1.92 \times 10^{3}$ & $4.63 \times 10^{6} \pm 1.68 \times 10^{4}$ & $3.06 \times 10^{4} \pm 1.16 \times 10^{3}$ & $1.55 \times 10^{6} \pm 8.18 \times 10^{3}$ \\
\cline { 2 - 5 } & $<1.23 \times 10^{3}$ & $2.63 \times 10^{5} \pm 4.91 \times 10^{3}$ & $1.63 \times 10^{5} \pm 1.84 \times 10^{3}$ & $3.26 \times 10^{5} \pm 5.47 \times 10^{3}$ \\
${ }^{134} \mathrm{Cs}$ & $9.10 \times 10^{6} \pm 1.94 \times 10^{4}$ & $1.04 \times 10^{8} \pm 9.03 \times 10^{4}$ & $1.12 \times 10^{7} \pm 1.98 \times 10^{4}$ & $3.40 \times 10^{7} \pm 3.83 \times 10^{4}$ \\
${ }^{60} \mathrm{Co}$ & $1.88 \times 10^{5} \pm 5.84 \times 10^{3}$ & $3.91 \times 10^{6} \pm 4.45 \times 10^{4}$ & $2.12 \times 10^{5} \pm 6.29 \times 10^{3}$ & $1.25 \times 10^{6} \pm 1.70 \times 10^{4}$ \\
${ }^{137} \mathrm{Cs}$ & $3.67 \times 10^{4} \pm 3.49 \times 10^{3}$ & $1.12 \times 10^{6} \pm 1.46 \times 10^{4}$ & $3.45 \times 10^{4} \pm 3.48 \times 10^{3}$ & $3.40 \times 10^{5} \pm 8.96 \times 10^{3}$ \\
${ }^{154} \mathrm{Eu}$ & $<1.81 \times 10^{4}$ & $4.39 \times 10^{6} \pm 1.18 \times 10^{5}$ & $8.87 \times 10^{5} \pm 1.32 \times 10^{4}$ & $4.74 \times 10^{6} \pm 3.64 \times 10^{4}$ \\
${ }^{155} \mathrm{Eu}$ & $1.99 \times 10^{4} \pm 3.91 \times 10^{3}$ & $3.08 \times 10^{5} \pm 1.01 \times 10^{4}$ & $2.07 \times 10^{4} \pm 4.55 \times 10^{3}$ & $1.08 \times 10^{5} \pm 1.06 \times 10^{4}$ \\
${ }^{125} \mathrm{Sb}$ & ${ }^{95} \mathrm{Zr}$ & \multicolumn{4}{c}{}
\end{tabular}

fuel burnup ${ }^{1}$. On the other hand, the activities of $\gamma$-emitters found in the washed and dissolved solutions of the same cladding, i.e., $\mathrm{H}-1(\mathrm{~W})$ and $\mathrm{H}-1(\mathrm{D})$ and $\mathrm{H}-2(\mathrm{~W})$ and $\mathrm{H}-2(\mathrm{D})$ are similar on the whole, except ${ }^{60} \mathrm{Co}$ and ${ }^{125} \mathrm{Sb}$. These results indicate that the $\gamma$-emitters including $\mathrm{Cs}$ and Eu isotopes were distributed similarly on the surface and in the interior of fuel cladding, regardless of fuel burnup.

Isotopic compositions of $\mathrm{U}, \mathrm{Pu}, \mathrm{Cs}$ and $\mathrm{Eu}$ in fuel cladding: Tables 3 and 4 show the isotopic compositions in atom $\%$ of $\mathrm{U}$ and $\mathrm{Pu}$ in the washed and dissolved solutions of H-1 and H-2 claddings measured by TIMS, respectively. Contributions of various isobars to the $\mathrm{U}$ and $\mathrm{Pu}$ fractions were identified by monitoring the mass peaks from 233-244. Data in the tables show that there is no isobaric effects from other elements. These data for $\mathrm{H}-1$ and $\mathrm{H}-2$ claddings are similar to those obtained from the high and low burnup spent fuels of a pressurized water reactor type ${ }^{6}$. As a result, we found that satisfactory chromatographic separation of $\mathrm{U}$ and $\mathrm{Pu}$ in the cladding samples, could be achieved by the produres in Fig. 2. Table-5 shows a comparison of the isotopic ratios for $\mathrm{U}, \mathrm{Pu}, \mathrm{Cs}$ and $\mathrm{Eu}$ in the washed and dissolved solutions of $\mathrm{H}-1$ and $\mathrm{H}-2$ claddings. As can be seen in the tables, all of the isotopic ratios for $\mathrm{U}, \mathrm{Pu}, \mathrm{Cs}$ and $\mathrm{Eu}$ in $\mathrm{H}-2(\mathrm{~W})$ and $\mathrm{H}-2(\mathrm{D})$, are similar to each other. On the other hand, in the case of those in $\mathrm{H}-1(\mathrm{~W})$ and H-1(D), there is a distinct difference between the two values. It may be inferred that the actinides and fission products were occluded into the surface oxide layer formed on the surface of the cladding through the repetition of the adsorption and adhesion of fuel and oxidation of the surface during irradiation ${ }^{1}$. Therefore, it can be concluded that the difference between the isotopic ratios in the washed solution to that in the dissolved solution decreases with the progression of the fuel burnup.

Quantities of $\mathbf{U}$ and Pu isotopes in fuel cladding: Tables 6 and 7 show the quantities of $\mathrm{U}, \mathrm{Pu}$ and their isotopes in the washed and dissolved solutions of $\mathrm{H}-1$ and $\mathrm{H}-2$ claddings as determined by IDMS. As shown in the tables, the quantities of $\mathrm{U}$ and $\mathrm{Pu}$ determined in the washed solution samples are much more than those of the dissolved solutions and the quantities of $\mathrm{U}$ and $\mathrm{Pu}$ found in $\mathrm{H}-2(\mathrm{~W})$ are higher than those found in $\mathrm{H}-1(\mathrm{~W})$. This means that the $\mathrm{U}$ and $\mathrm{Pu}$ in the claddings are mainly present on the surface and only a small amount is

\begin{tabular}{ccccc} 
& \multicolumn{5}{c}{ TABLE-3 } \\
& \multicolumn{5}{c}{ ASOTOPIC COMPOSITIONS OF U SEPARATED FROM CLADDING SAMPLES } \\
\cline { 2 - 5 } Sample & ${ }^{234} \mathrm{U}$ & ${ }^{235} \mathrm{U}$ & ${ }^{236} \mathrm{U}$ & \\
\cline { 2 - 5 } & $0.025 \pm 0.003$ & $0.960 \pm 0.003$ & $0.510 \pm 0.004$ & $98.501 \pm 0.006$ \\
H-1(W) & $0.028 \pm 0.006$ & $0.774 \pm 0.008$ & $0.583 \pm 0.010$ & $98.596 \pm 0.059$ \\
H-1(D) & $0.026 \pm 0.002$ & $0.675 \pm 0.006$ & $0.685 \pm 0.006$ & $98.613 \pm 0.014$ \\
H-2(W) & $0.026 \pm 0.008$ & $0.699 \pm 0.007$ & $0.673 \pm 0.006$ & $98.596 \pm 0.019$ \\
H-2(D) & &
\end{tabular}

\begin{tabular}{|c|c|c|c|c|c|}
\hline \multirow{3}{*}{ Sample } & \multicolumn{4}{|c|}{$\begin{array}{c}\text { TABLE-4 } \\
\text { OTOPIC COMPOSITIONS OF Pu SEPARATED FROM CLADDING SAMPLES }\end{array}$} & \\
\hline & \multicolumn{5}{|c|}{ Atom $(\%)$} \\
\hline & ${ }^{238} \mathrm{Pu}$ & ${ }^{239} \mathrm{Pu}$ & ${ }^{240} \mathrm{Pu}$ & ${ }^{241} \mathrm{Pu}$ & ${ }^{242} \mathrm{Pu}$ \\
\hline $\mathrm{H}-1(\mathrm{~W})$ & $1.242 \pm 0.012$ & $62.127 \pm 0.040$ & $22.991 \pm 0.031$ & $6.663 \pm 0.030$ & $6.978 \pm 0.030$ \\
\hline $\mathrm{H}-1$ (D) & $3.676 \pm 0.025$ & $55.792 \pm 0.038$ & $25.018 \pm 0.034$ & $7.865 \pm 0.016$ & $7.650 \pm 0.021$ \\
\hline $\mathrm{H}-2(\mathrm{~W})$ & $2.065 \pm 0.039$ & $52.964 \pm 0.030$ & $23.126 \pm 0.018$ & $10.350 \pm 0.010$ & $11.495 \pm 0.013$ \\
\hline $\mathrm{H}-2(\mathrm{D})$ & $2.227 \pm 0.018$ & $52.399 \pm 0.034$ & $23.055 \pm 0.027$ & $10.673 \pm 0.012$ & $11.646 \pm 0.014$ \\
\hline
\end{tabular}

TABLE-5

COMPARISON OF U, Pu, Cs AND Eu ISOTOPIC RATIOS IN CLADDING SAMPLES

\begin{tabular}{ccccccc}
\hline \multirow{2}{*}{ Sample } & \multicolumn{3}{c}{ Atom ratio } & \multicolumn{2}{c}{ Activity ratio } \\
\cline { 2 - 7 } & ${ }^{235} \mathrm{U} /{ }^{236} \mathrm{U}$ & ${ }^{235} \mathrm{U} /{ }^{238} \mathrm{U}$ & ${ }^{239} \mathrm{Pu} /{ }^{240} \mathrm{Pu}$ & ${ }^{239} \mathrm{Pu} /{ }^{242} \mathrm{Pu}$ & ${ }^{134} \mathrm{Cs} /{ }^{137} \mathrm{Cs}$ & ${ }^{155} \mathrm{Eu} /{ }^{154} \mathrm{Eu}$ \\
\hline $\mathrm{H}-1(\mathrm{~W})$ & 1.882 & 0.010 & 2.702 & 8.903 & 0.007 & 0.196 \\
$\mathrm{H}-1(\mathrm{D})$ & 1.328 & 0.008 & 2.230 & 7.293 & 0.003 & 0.162 \\
$\mathrm{H}-2(\mathrm{~W})$ & 0.985 & 0.007 & 2.290 & 4.608 & 0.045 & 0.286 \\
$\mathrm{H}-2(\mathrm{D})$ & 1.039 & 0.007 & 2.273 & 4.499 & 0.046 & 0.271 \\
\hline
\end{tabular}




\begin{tabular}{cccccc}
\hline & \multicolumn{5}{c}{ TABLE-6 } \\
& \multicolumn{7}{c}{ DETERMINATION OF U AND ITS ISOTOPES IN CLADDING SAMPLES BY IDMS } \\
\cline { 2 - 6 } Sample & ${ }^{234} \mathrm{U}$ & $\mathrm{U}(\mu \mathrm{g} / \mathrm{g}$-sample) & Total \\
& 0.12 & 4.57 & 2.45 & 474.58 & $481.7 \pm 19.0$ \\
H-1(W) & 0.03 & 0.68 & 0.53 & 90.25 & $91.5 \pm 4.0$ \\
H-1(D) & 2.34 & 61.03 & 62.19 & 9029.44 & $9155 \pm 275$ \\
H-2(W) & 0.01 & 0.35 & 0.34 & 49.51 & $50.2 \pm 3.0$ \\
H-2(D) & &
\end{tabular}

TABLE-7

DETERMINATION OF PU AND ITS ISOTOPES IN CLADDING SAMPLES BY IDMS

\begin{tabular}{|c|c|c|c|c|c|c|}
\hline \multirow{2}{*}{ Sample } & \multicolumn{6}{|c|}{$\mathrm{Pu}(\mu \mathrm{g} / \mathrm{g}$-sample) } \\
\hline & ${ }^{238} \mathrm{Pu}$ & ${ }^{239} \mathrm{Pu}$ & ${ }^{240} \mathrm{Pu}$ & ${ }^{241} \mathrm{Pu}$ & ${ }^{242} \mathrm{Pu}$ & Total \\
\hline H-1(W) & 0.09 & 4.40 & 1.64 & 0.48 & 0.50 & $7.1 \pm 1.0$ \\
\hline H-1(D) & 0.01 & 0.17 & 0.08 & 0.02 & 0.02 & $0.3 \pm 0.03$ \\
\hline $\mathrm{H}-2(\mathrm{~W})$ & 4.40 & 113.35 & 49.70 & 22.34 & 24.91 & $214.7 \pm 21$ \\
\hline $\mathrm{H}-2(\mathrm{D})$ & 0.08 & 1.78 & 0.78 & 0.36 & 0.40 & $3.4 \pm 0.5$ \\
\hline
\end{tabular}

distributed in the interior of the cladding, in addition, the contents of $\mathrm{U}$ and $\mathrm{Pu}$ deposited on the surface of the cladding are increase with increasing fuel burnup.

\section{Conclusion}

An analytical process has been developed for the determination of the $\mathrm{U}, \mathrm{Pu}, \mathrm{Cs}$ and $\mathrm{Eu}$ isotopes in the fuel cladding using isotope dilution mass spectrometry and $\gamma$-ray spectrometry. Two-step dissolution procedure using HF and aqua regia was very effective for the dissolution of fuel cladding. The $\mathrm{U}$ and $\mathrm{Pu}$ in the fuel claddings were purely separated without contributions of various isobars by an anion exchange chromatography. The isotopic compositions for $\mathrm{U}, \mathrm{Pu}, \mathrm{Cs}$ and $\mathrm{Eu}$ on the surface and in the interior of high burnup fuel cladding, are similar to each other. On the other hand, in the case of those of low burnup fuel cladding, there was a distinct difference between the two values. The $\mathrm{U}$ and $\mathrm{Pu}$ in the cladding are mainly present on the surface and only a small amount is distributed in the interior of the cladding, while the $\mathrm{Cs}$ and Eu isotopes were distributed similarly on the surface and in the interior of the cladding, regardless of fuel burnup.

\section{REFERENCES}

1. T. Hirabayashi, T. Sato, C. Sagawa, N.M. Masaki, M. Saeki and T. Adachi, J. Nucl. Mater., 174, 45 (1990).

2. I.L. Jenkins and P.E. Brown, Radiochim. Acta, 36, 25 (1984).

3. J.S. Kim, Y.S. Jeon, S.D. Park, B.C. Song, S.H. Han and J.G. Kim, Nucl. Eng. Technol., 38, 301 (2006).

4. Z. Goncalves and H. Munzel, J. Nucl. Mater., 170, 261 (1990).

5. M. Bertaux, P. Bienvenu, O. Provitina, C. Point, J.B. Bilcot, E. Brochard, S. Pontremoli and N. Arnal, Analytical Improvements for Long-Lived Radionuclides Determination in Zircaloy Hull. ATALANTE 2008, May 19-22 (2008).

6. J.S. Kim, Y.S. Jeon, S.D. Park, S.H. Han and J.G. Kim, J. Nucl. Sci. Technol., 44, 1015 (2007). 